\title{
Possible toxic metal exposure of prehistoric bronze workers
}

\author{
M HARPER \\ From the TUC Centenary Institute of Occupational Health, London School of Hygiene and Tropical Medicine, \\ London WCIE 7HT, UK
}

ABSTRACT An attempt has been made to assess the possible occupational exposure to arsenic, lea and mercury during the Bronze Age. Archaeological, metallurgical, and historical evidence is coms bined to form a picture of the potential toxic hazards. In the case of arsenic a definite picture emerges of the effect of toxicity as a useful material is abandoned for health reasons on discoveriy of an acceptable alternative.

Sophisticated methods to determine the extent of occupational exposure to toxic elements such as arsenic, lead, and mercury are now available and are used to ensure the continued health of the workforce. From the earliest beginnings of metalworking the requirement for certain metals and alloys often involved a major personal hazard that was accepted as a normal consequence of the employment even in the most acutely debilitating cases. The results of chronic exposure may not even have been recognised as an occupational hazard, especially in view of the generally shorter lifetimes through disease and accident. There are three main sources of evidence from which it is possible to attempt to build up a picture of past metallurgical processes and thus to gain an understanding of occupational exposures by relating this evidence to our modern knowledge of metallurgy and process chemistry. These are literary and epigraphical sources, smelting sites and associated archaeological remains, and, finally, the surviving metal objects themselves. This paper attempts to examine the Bronze Age bronze working in detail to assess the potential hazard in producing arsenical copper alloys and high lead bronzes and in the mercury gilding of bronze.

The authors of mediaeval and classical texts have left descriptions of materials and processes that are often sufficiently detailed to construct a clear picture of the technology used. Apart from a slow evolution in efficiency basic techniques have changed little and it may be assumed that similar processes were used before recorded history. Metal workers have tradi-

Accepted 13 October 1986 tionally formed a rather closed shop disseminating techniques verbally through a complex elite of mas ters and apprentices. That religious ritual and secrecot surrounded their work is evident from the close cons nection with the origins of alchemy. ${ }^{1}$ The frequent breakdown in this succession has often been lamented when important innovations have been lost. The \&o lation of metalworking sites in remote and sparsely inhabited areas would have further slowe the communication of new ideas.

The evidence of investigations of archaeologica sites has tended to confirm this picture of remarkab? early achievements in technology with subsequenf conservation or slow evolution, later improvements concentrating principally on the efficiency of furnace design and the production of higher quality alloys Nevertheless, one important advance in Bronze Age technology is dealt with in some detail in this paper $-\mathbb{D}$ that is, the transfer from arsenical copper alloys t⿳⺈ leaded tin bronze with a switch from forging to casi ing. Finally, metallurgical studies of the artefacts pro duced, by chemical analysis and microscopica examination, sheds further light on both the tech niques of working and the compositions of the alloys When all of the available evidence is collated a reas sonably consistent interpretation concerning the potential for toxic exposure may be deduced.

\section{Arsenical copper alloys}

The earliest use of copper dates from around the ninth to the seventh millenia BC in western Iran and Anatolia. ${ }^{2}$ This would have necessitated cold workin of native copper as melting separates out gangure components considerably reducing the hardness. No 
great hardness can be achieved without the combination of hammering and annealing that became the basis of metalworking for many centuries. Native copper occurs in intimate association with the oxidised copper minerals malachite, azurite, and cuprite. The former two minerals were often used as glazes, and copper smelting probably arose from the accidental reduction of these ores in pottery kilns. Smelting became widespread by $3500 \mathrm{BC}$, producing a copper of relatively high purity at sites such as Timna in Israel from oxidised copper ores with a low arsenic content. The preponderance of artefacts with a much higher $(>2 \%)$ arsenic content is such that a deliberate process of arsenic inclusion must be envisaged. ${ }^{2}$ Although it is true that certain copper sulphide minerals have a naturally high arsenic content, these minerals must first be converted to oxides by roasting in air before smelting, a process in which most of the arsenic would be lost by sublimation of the oxide. At the Swedish Boliden Mining Company copper ore containing $9 \%$ arsenic is reduced to $0.2 \%$ by roasting. ${ }^{3}$ To produce arsenical copper alloys with up to $7 \%$ arsenic deliberate additions of arsenical copper sulphides or of arsenic sulphides to the melting mix would be required. ${ }^{3}$ In this connection it should be noted that the easily recognisable, brightly coloured sulphides orpiment and realgar are to be found associated with the oxidised copper ores whereas arsenical copper sulphides would occur at deeper levels in the mine. An unusual "earth" added to copper is described by Theophrastus as whitening the colour of copper. Aristotle describes a similar addition and notes that the failure of the discoverer to instruct anyone else in the process meant that subsequent alloy production from this region was of an inferior type. ${ }^{4}$ Under reducing conditions most of the arsenic below a concentration of $7 \%$ is retained within the melt and lost only slowly from the surface ${ }^{2}$; few ancient artefacts exceed this value.

The presence of arsenic has been shown to have little effect on the cast or annealed condition, yet even a slight addition raises the maximum strength of hammered copper enormously, the hardness rising with the amount of arsenic (fig 1) and the amount of working (fig 2) in a similar fashion to the effect of tin on bronze. Such an effect on a hammered cutting edge would be immediately noticeable and efforts would have been made to reproduce the conditions. Early Bronze Age smiths usually improved the hardness of cast arsenical copper axes and chisels from a Vickers hardness of $70 \mathrm{HV}$ to $100 \mathrm{HV}$ by working. Most of these deliberate alloys fall within a range of $1-4 \%$ averaging around $2 \%$, suggesting a relative control of composition within narrow limits which ranks as a major technological achievement. ${ }^{5}$ Increasing the arsenic content over $3.5 \%$ allows a hardness of 150

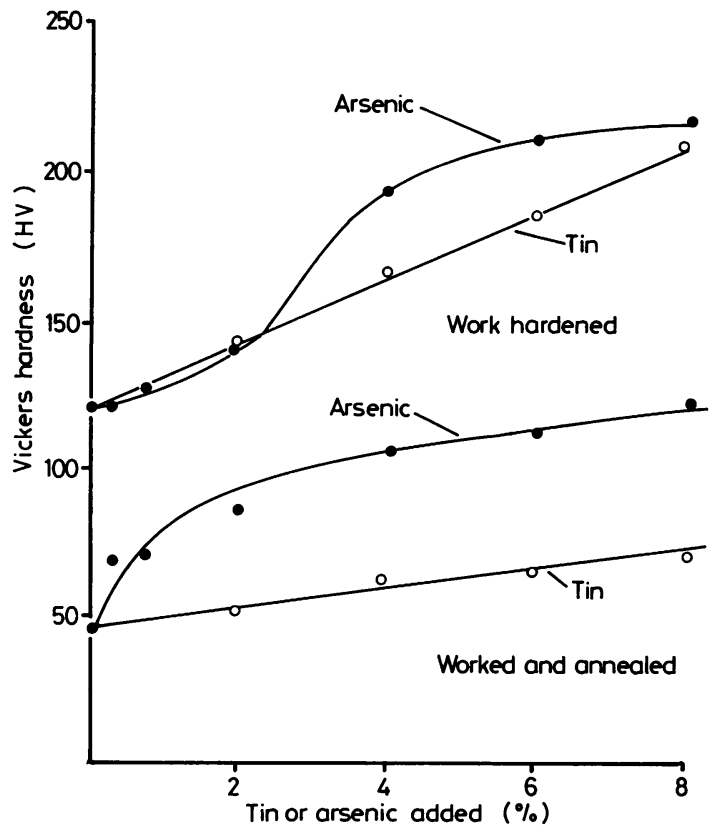

Fig 1 Effect of tin or arsenic addition on hardness of copper (from data in Tylecote ${ }^{6}$ ).

HV so that some sort of disadvantage must also be present.

In the later stages of smelting and refining considerable quantities of oxygen may dissolve in copper resulting in copper oxide as a grain boundary eutectic, seriously affecting the cold workability. When present, arsenic is preferentially oxidised if the liquid metal is exposed to the air. Arsenic oxide forms an immiscible separate phase that either remains as inclusions in the alloy or sublimes from the surface. ${ }^{3}$ In high $(>2.5 \%)$ arsenic alloys the oxide inclusions lead to brittleness, the reason why such alloys are not in use today. Such intense alloying was used only for a brief period around the time of the introduction of high tin bronzes, probably as an attempt at competition.

The early Bronze Age in Britain is marked by the first appearance of a similar arsenical copper tradition with artefacts originating in Ireland or from the Continent (characterised by high nickel contents). Tin bronzes with much lower contents of impurities soon began to displace the Irish artefacts, suggesting both an improvement in smelting technique and a greater use of local ores. ${ }^{6}$ Throughout the entire European and Middle Eastern world tin bronzes appeared in preference to arsenical coppers within a period of $300-400$ years. This is despite the fact that there is only a marginal difference in mechanical properties between the two. The original rather high lead con- 


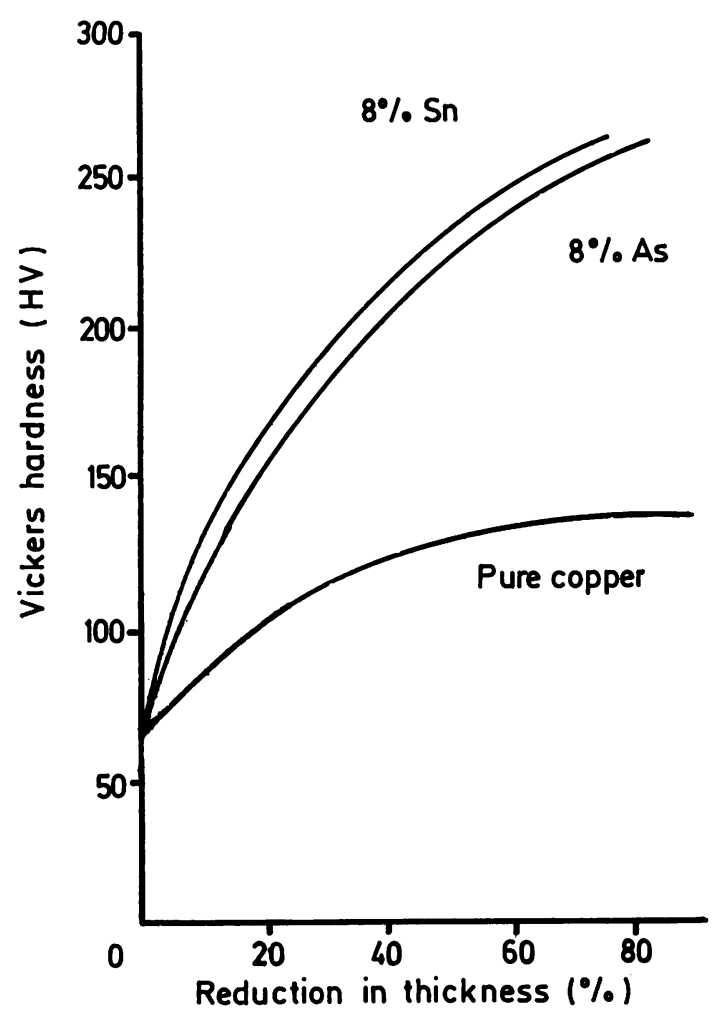

Fig 2 Effect of cold working on hardness of copper alloys (after Tylecote ${ }^{2}$ ).

tent bronzes would have possessed hardnessess around $120 \mathrm{HV}, 170 \mathrm{HV}$ being only achieved by later lower lead, higher tin alloys. Further, the reduced solubility of tin at low temperatures has a deleterious effect on cold workability whereas arsenical coppers may readily be worked over a wide range of temperatures without the embrittlement due to the appearance of a second phase. ${ }^{3}$ In addition, copper ores are often associated with those of arsenic whereas tin ores are extremely rare in the area under consideration. Transport from the Danube, the Vosges, or from Cornwall must have exacted a heavy premium on price. The resurgence of arsenical copper artefacts is often seen in the early part of the middle and late Bronze Age, presumably due to the frequent interruptions in trade. ${ }^{2}$

The general toxicity of arsenical materials would have been recognised by early miners. Agricola warns against the effects of "cadmia" as late as the fifteenth century AD, when a sublimate of arsenical oxides formed during the process of breaking rocks with underground fires was said to attack wounds and ulcers as well as feet, hands, lungs, and eyes. ${ }^{7}$ Classical authors often refer to the necessity for chimneys as an adjunct to ore mineral roasting in order to disperse the noxious vapours of sulphur and arsenic. Arsenical oxide is readily lost from arsenical coppe? during the process of hot forging as an extremel $\vec{F}$ toxic white fume. ${ }^{3}$ The surface/volume ratio of smaller objects and the time required in forging suge gests a correspondingly higher loss-for instance, hal $\overline{\bar{s}}$. berd rivets are consistently found to be softer and to have lower arsenic contents than the corresponding blades. ${ }^{6}$

Even in relatively modern plants with fumb arresting equipment considerable contamination can occur and anyone smelting arsenical copper materiadt under crude conditions without such highlos sophisticated ventilation control and extremelo stringent personal hygiene would run a strong risk of death by poisoning. The corrosive nature of arsenie oxide would probably have been the greates $\vec{\phi}$ deterrent to the continued use of arsenic even if acutis deaths were somehow avoided.

\section{High lead bronzes}

The passage from arsenical copper is easily found io the substantially additive effects of tin and arsenic on the hardness of copper. The so called arsenicat bronzes containing $1-2 \%$ tin and $1-4 \%$ arsenic are found in many areas during the transition. These alloys were still produced by the older traditiongers method of forging rather than casting. ${ }^{2}$ the cementation process of bronze manufacture whero the oxides of tin and copper are smelted togethe makes use of the lower melting point of copper onc 8 tin has begun to diffuse into the metal. The additiof of lead increases the fluidity of the alloy and the comb posite alloy produced may be easily cast. Most of the late Bronze Age artefacts were cast as double (two part) moulds and needed little, if any, hammering. The tin content of both archaic and classical Gree statuettes is well defined ${ }^{8}$ within $6-10 \%$, whereas the lead contents are highly variable (fig 3 ), the distribu讘. tion suggesting that no specific lead content was preg ferred. Vessels were normally made from sheet metal and are thus unleaded, although handles were cast and are leaded. Bronze armour which would require working to shape is also unleaded.

The late Bronze Age in Britain began with an allo containing $7 \%$ or more of lead. This stage did not las and the lead content was progressively reduced bo dilution with lead free scrap in a similar fashion to the reduction of the arsenic content of alloys during the early Bronze Age. Variations in the trace metal con tent support this view and substantial traces arsenic, antimony, nickel, and silver were introduce by Continental contamination. On the whole the lead content of bronze had declined to $2-3 \%$ by the end of 


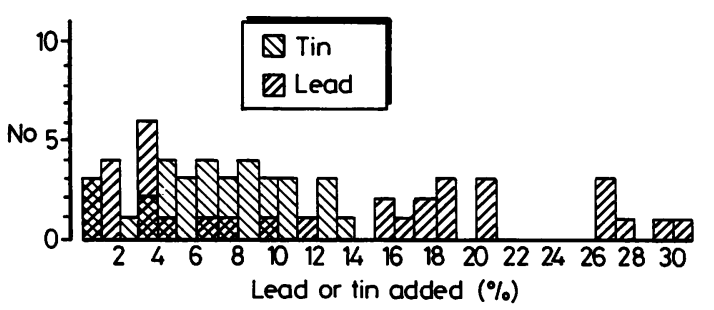

Fig 3 Lead and tin content of Hellenistic bronze statues (after Craddock ${ }^{8}$ ).

the late Bronze Age. As this is the optimum concentration to facilitate casting the excess may have been a cheap diluent for an expensive metal. ${ }^{6}$

As may be seen from fig 4 lead appears in the finished alloy as a discrete phase. Lead is almost totally insoluble in copper so that the bronze will crystallise with an intergranular liquid from which the lead will solidify as the temperature falls during casting. The molten bronze would normally have been cast at around $1000^{\circ} \mathrm{C}$, certainly far higher than the melting point of lead $\left(328^{\circ} \mathrm{C}\right)$. Evaporation of the lead will occur from the globules which are concentrated at the metal surface. ${ }^{9}$ Oxidation will also take place during cooling and subsequent processing will liberate lead oxide dusts. The bronzes described by Pliny are all of a strictly defined composition so that the highly variable lead contents of the finished products may be due to variable losses in processing. ${ }^{4}$ Once again the lack of attention to ventilation and personal hygiene would have presented an exposure hazard to this section of the workforce.

\section{Mercury gilding on bronze}

Mercury ores occur at Ephesus in Anatolia and at Almaden in Spain. The mercury was extracted by displacement from the sulphide ore mineral cinnabar by copper in the presence of vinegar. ${ }^{4}$ The pure metal was released from its copper amalgam by heating and condensation. Mercury gilded bronze is known from the fourth to first century BC in classical Greece. ${ }^{8}$ There are two possible techniques for the gilding of copper and silver using mercury. In the first the surface of the base metal object is amalgamated by rubbing mercury on to it followed by the application of gold leaf. In the second, used by the Greeks, a prepared gold mercury amalgam is spread over the base metal surface. In either case pretreatment with a mercury salt is helpful and the final stage is to heat the metal to evaporate the mercury leaving a continuous and strongly adherent film of gold on the surface. ${ }^{9}$ Other metals also form amalgams with mercury, the saturated weight percentage solution $\left(\right.$ at $20^{\circ} \mathrm{C}$ ) being $2.15 \%$ for zinc, $0.61 \%$ for tin, and $1.3 \%$ for lead compared with $0.00032 \%$ for copper. There is a considerable likelihood of a solution of the first three metals spoiling the final gilding. In the case of lead, which is concentrated as globules on the surface rather than in solution in the copper, melting occurs at a temperature below the boiling point of mercury. For

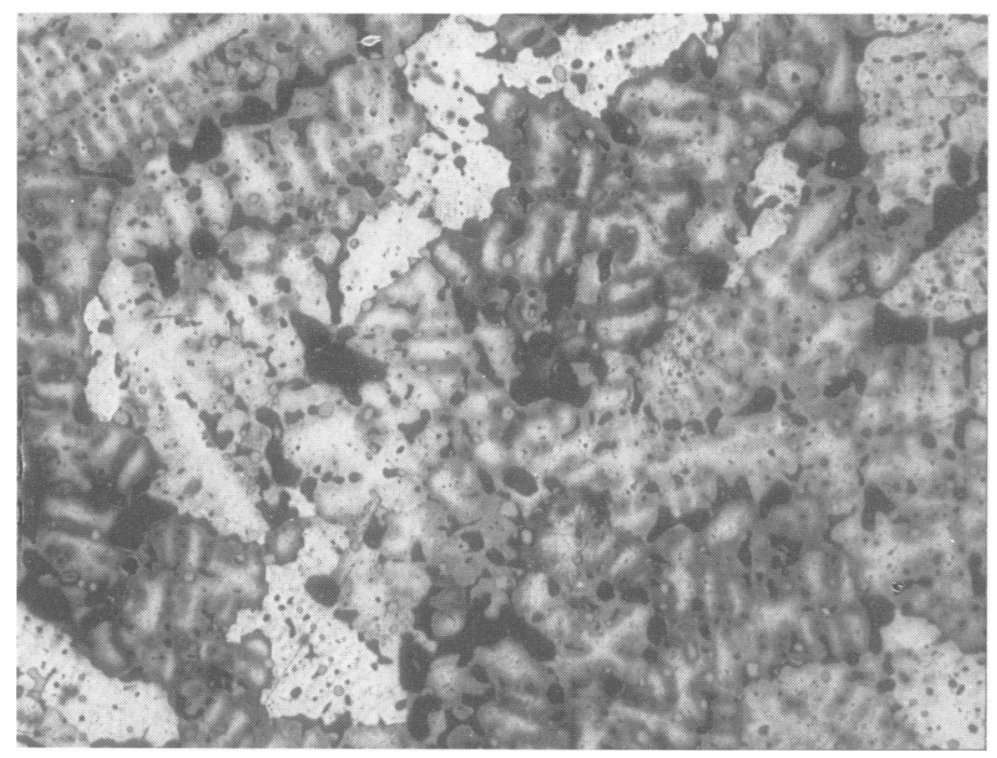

Fig 4 Photomicrograph of $8 \%$ leaded tin bronze showing discrete lead grains (small rounded light grey areas) $\times 100$. 
these reasons gilding was confined to low tin bronzes that were lead free or pure copper. ${ }^{8}$ The technique became widespread during the later Roman Empire (second to third century AD). ${ }^{9}$ The entire process is fraught with the potential for mercury poisoning, exposure being a virtual certainty during both the refining of mercury and the final stage gilding.

\section{Conclusions}

Since toxic exposure to any of the three metals was equally likely it is of interest to conjecture why the decline in arsenic use was so rapid and yet lead and mercury continued in their applications throughout their subsequent history. The answer probably lies in the differing effects of chronic toxicity and the subsequent ease of establishing a definite causal relation between symptoms and exposure.

A common effect of chronic arsenic poisoning is dermatitis and hyperkeratosis sometimes associated with arsenical melanosis, which may lead to the development of skin cancer. These symptoms would have been readily and obviously associated with arsenic exposure. In the long term another important manifestation of chronic arsenic poisoning is the development of a peripheral neuritis which may lead to weakness in the legs and feet. In this connection it should be noted that the patron gods of craftsmen such as the Greek Hephaistos, Roman Vulcan, Teutonic Wieland, Scandinavian Völunder, and the Finnish Ilmarinen are all lame. Such a widespread association of a particular symptom with a single occupation has led to the suggestion that this could have resulted from arsenical neuropathy. ${ }^{10}$

The chronic effects of lead toxicity such as renal disease and peripheral neuropathy mainly affecting the motor nerves may take many years to develop and may have passed unnoticed because of the high degree of exposure to lead from other sources, especially likely during the Roman period. The evidence for the separate identification of lead induced colic by contemporary practitioners is equivocal and $\overline{\bar{\alpha}}$ the connection between symptom and cause is unlikely to have been made. ${ }^{10}$ The onset of the symp-? toms of chronic mercury poisoning is often similarly $\overrightarrow{\vec{F}}$ delayed. Such symptoms as tremor and erethism aref again unlikely to have been correctly attributed given등 the prevailing state of medical knowledge even if they were to be separately identified from the general stan- $\bar{\Phi}$ dard of health.

There is certainly no direct reference to any of thesees diseases in the ancient literature and the best evidence $\vec{\circ}$ for the possibility that recognisable arsenic toxicity existed is the indirect inference that may be drawn $\vec{\omega}$ from the history of usage. So far as other evidence for 0 chronic metal poisoning is concerned it is only possi- $-\frac{\mathbb{D}}{3}$ ble to draw conclusions in the manner that has been attempted here - that is, based on the probability of exposure estimated from a consideration of the pro- $\vec{O}$ cesses and materials.

\section{References}

1 Lindsay J. The origins of alchemy in Graeco-Roman Egypt. Lon-O don: Muller, 1970:212-8.

2 Tylecote RF. A history of metallurgy. London: The Metals Soci-음 ety, 1976:1-39.

3 Charles JA. Early arsenical bronzes-a metallurgical view. Amer-

ican Journal of Archaeology 1967;71:20-6.
4 Healy JF. Mining and metallurgy in the Greek and Roman wodd London: Thames and Hudson 1978;158, 210-2.

5 Craddock PT. The composition of the copper alloys used by The Greek, Etruscan and Roman civilisations. 1. The Greeks fore the archaic period. Journal of Archeological Science? 1976;3:93-113.

6 Tylecote RF. The prehistory of metallurgy in the British Isles. Lon $\frac{\text { QD }}{\mathrm{D}}$ don: The Institute of Metals, 1986:10-42.

7 Agricola G. De re metallica. New York: Dover Publications, 1950:214.

8 Craddock PT. The composition of the copper alloys used by the Greek, Etruscan and Roman civilisations. 2. The archaic, clas? sical and Hellenistic Greeks. Journal of Archeological Sciencẹ 1977;4:103-23.

9 Lins PA, Oddy WA. The origins of mercury gilding. Journal of Archaeological Science;1975;2:365-73.

10 Nriagu JO. Lead and lead poisoning in antiquity. New York므 Wiley, 1983:316-7, 379-80. 